\title{
Expression of the orphan nuclear receptor ERRa is under circadian regulation in estrogen-responsive tissues
}

\author{
B Horard, B Rayet ${ }^{1}$, G Triqueneaux, V Laudet, F Delaunay ${ }^{1}$ and J-M Vanacker \\ Laboratoire de Biologie Moléculaire de la Cellule, CNRS UMR 5161, IFR128 Biosciences Lyon-Gerland, Ecole Normale Supérieure de Lyon, 46 allée \\ d'Italie, 69007 Lyon, France \\ 1 Université de Nice-Sophia Antipolis, CNRS UMR 6078, 284 ch. du Lazaret, 06230, Villefranche-sur-Mer, France \\ (Requests for offprints should be addressed to J-M Vanacker; Email: jvanacker@valdorel.fnclcc.fr) \\ (B Horard and J-M Vanacker are now at Laboratoire Genome et Cancer, INSERM EMI0229, CRLC Val d'Aurelle-Paul Lamarque, 34298 Montpellier \\ cedex 5, France)
}

\begin{abstract}
Circadian gene expression has been demonstrated in many tissues and involves both positive and negative regulatory loops. The potential interferences of circadian rhythmicity with other well-known biologic rhythms, such as the ovarian cycle, at least in part controlled by estrogens, has not been questioned. The estrogen receptor-related receptor (ERR) $\alpha$ is an orphan nuclear receptor that is widely expressed in estrogen-responsive tissues such as liver, uterus and bone. In addition, expression of the $E R R a$ gene has been proposed to be transcriptionally controlled by estrogens in the uterus. Here we show that the expression of ERRa displays a circadian rhythmicity in liver, bone and uterus. This is in contrast to other uterine estrogen-regulated genes. Analysis of clock/clock mutant mice shows that $E R R a$ is an output gene of the circadian clock oscillator. The expression of clock-control genes, such as Bmal1 and Rev-erba, also displays diurnal oscillations in the uterus, but not in bone. In this tissue, however, Per2 displayed a rhythmic expression, altogether suggesting unconventional loops in the regulation of circadian rhythm in bone.
\end{abstract}

Journal of Molecular Endocrinology (2004) 33, 87-97

\section{Introduction}

Circadian regulation of gene expression is a general phenomenon that has been demonstrated in many organisms ranging from plants to animals (Albrecht \& Eichele 2003, Schultz \& Kay 2003). It is thought to help organisms anticipate the cyclic changes in the ambient environment by promoting adequate responses in terms of physiological and behavioral processes. In mammals, daily light signals are conveyed from the retina to the suprachiasmatic nuclei (SCN), where they reset a molecular clock. The SCN then signals to peripheral organs, such as the liver, where autonomous circadian clocks have been demonstrated. The peripheral clock present in the liver can also be reset by humoral signals connected to food availability (Damiola et al. 2000, Stokkan et al. 2001). The molecular clock itself comprises a positive limb involving CLOCK and
BMAL proteins that promote transcriptional activation of the members of the negative limb such as Per and Cry genes (reviewed in Schibler \& Sassone-Corsi 2002, Albrecht \& Eichele 2003, Fu \& Lee 2003, Van Gelder et al. 2003). In turn, the products of these genes repress the activation driven by the CLOCK-BMAL heterodimeric complex. This feedback loop also regulates the rhythmic expression of the Rev-erba orphan nuclear receptor, which downregulates the expression of Bmal1 and thereby contributes to the robustness of the oscillation (Preitner et al. 2002). The deficiency in one or several of these core genes in natural or engineered mouse mutants results in dramatic consequences concerning the rhythmicity of circadian activity and/or rhythmic gene expression (for examples, see van der Horst et al. 1999, Bunger et al. 2000, Oishi et al. 2000, Preitner et al. 2002, Oster et al. 2003). 
The mechanisms by which the molecular clock cycles has thus recently gained understanding, and output genes (that is, genes that are regulated by but are not regulating the central clock) have been identified by cDNA array technology (for example, see Grundschober et al. 2001, Panda et al. 2002, Ueda et al. 2002; reviewed in Delaunay \& Laudet 2002). However, very few pathways that precisely connect circadian oscillators to physiological outputs have been established.

It has long been recognized that the circulating levels of diverse hormones vary according to a day-to-night rhythm. For instance, mammalian blood concentrations of testosterone and estrogens are maximum during the late part of the night, whereas follicle-stimulating hormone (FSH)/ luteinizing hormone (LH) levels peak in the afternoon (Krajnak et al. 1998, Ankarberg \& Norjavaara 1999, Mitamura et al. 2000). Conversely, estrogens and testosterone, as shown by heterochronic exposure, influence the circadian rhythm in rodents by modulating their physical activities (Morin et al. 1977, Jechura et al. 2000). However, the circulating levels of various hormones are also regulated according to the ovarian cycle (lasting 4 days in mice). Superimposition of circadian and ovarian cycles has been shown for the expression of pituitary-expressed $\mathrm{FSH} / \mathrm{LH}$, which is maximum in the afternoon of the day of proestrus under the influence of SCN-produced vasoactive intestinal polypeptide (Krajnak et al. 1998). The situation is less clear in the uterus, which is a typical estrogenresponsive tissue. Indeed, sex hormones, particularly estrogens, exert profound cyclic influences on this organ, in which they are responsible for proliferation and differential gene expression, in preparation for the conceptus implantation. The expression of clock controlling genes has been demonstrated in the uterus (Johnson et al. 2002), but it is not known whether their mRNA oscillates, as it does in other peripheral tissues. The existence of a peripheral clock in the uterus has therefore not been formally demonstrated. This remark also holds for bone, another tissue that is highly sensitive to estrogens, although it does not undergo cyclic proliferation and differentiation. Nevertheless, bone supports an equilibrium between formation and resorption, the rate of which has been shown to be more elevated during the night (Srivastava et al. 2001, Siebel et al. 2002 and references therein).
The estrogen receptor-related receptors (ERR) belong to the nuclear receptor superfamily of ligand-dependent transcription factors (Giguère et al. 1988, Hong et al. 1999; for reviews, see Giguère 2002, Laudet \& Gronemeyer 2002). In contrast to the estrogen receptors to which they are structurally related (hence their names), their transcriptional activities are not regulated by estrogens nor by any identified natural ligand (see Horard \& Vanacker 2003 for a review). However, the expression of ERRa has been suggested to be regulated by estrogens in mouse uterus (Liu et al. 2003). ERRa is expressed in a variety of tissues, during both embryonic development and adult life. For instance, its mRNA has been detected in liver, uterus and bone, both in the embryo and in the adult (Giguère et al. 1988, Bonnelye et al. 1997a). In the latter tissue, ERR $\alpha$ has been suggested to exert a role in controlling proliferation and differentiation ex vivo (Bonnelye et al. 2001), and it activates the expression of osteopontin, an osteoblastic differentiation marker (Vanacker et al. 1998). Furthermore, ERR $\alpha$ might control bone mineral density in vivo (B Horard and J-M Vanacker, unpublished).

In this report, we show that ERRa mRNA expression oscillates in liver. The circadian nature of the variations of ERRa expression was assessed using Clock mutant mice, which display constant ERRa mRNA levels over time. The expression of $E R R a$ in the uterus was also found to be circadian, as was that of Bmall and Rev-erba. Surprisingly, these two genes were not cyclically expressed in bone. However, oscillations of ERRa and Per2 expression demonstrate the existence of a circadian rhythm at the level of mRNA expression in this tissue.

\section{Materials and methods}

\section{Animals}

Female OF1 mice aged 6 weeks (Charles River Laboratory, Lyon, France) were entrained on a L13/D11 cycle for 1 week before the day of experiment. For light-dark (LD) experiments, animals were housed in the same conditions. For constant darkness (DD) conditions, animals were transferred to DD at the start of the normal photoperiod (corresponding to CT0). Animals were killed by cervical disruption at $4 \mathrm{~h}$ intervals $(n=3-4)$. 
Hind limb long bones were flushed with PBS to eliminate the bone marrow. Tissues were immediately frozen in liquid nitrogen after collection. Organs were mechanically minced in liquid nitrogen, and RNAs were purified by guanidinium thiocyanate/phenol/chloroform extraction. RNA samples extracted from male clock mutants and wild-type littermates were a generous gift of Joseph S Takahashi (Northwestern University, Evanston, IL, USA).

\section{DNA microarray experiments}

Livers from male $\mathrm{C} 57 \mathrm{Bl} / 6$ mice kept on an $\mathrm{LD}$ $12 / 12$ cycle were dissected at $4 \mathrm{~h}$ intervals from zeitgeber time (ZT) 0 to ZT20. For each time point, liver samples from ten animals were pooled, and total RNA was prepared. For each sample, cDNA synthesis, biotin labeling of cRNA and hybridization to murine U74Av2 Genechips were performed in duplicate according to the recommendations of the manufacturer (Affymetrix, High Wycombe, UK). Gel files were condensed by using MAS4 algorithm (Affymetrix). Genes exhibiting an average differential intensity above 2 and a temporal variation in expression were identified after ANOVA with a significance threshold set at $P<0 \cdot 01$, using the GenAnova software. ERRa was represented by two probe sets (102145_f_at and 103964_at) that gave similar expression profiles.

\section{RT-PCR}

An amount of $2 \mu \mathrm{g}$ total RNA was DNaseIdigested and retrotranscribed in a final volume of $80 \mu \mathrm{l}$ with MMTV retrotranscriptase (Fermentas, Souffelweyersheim, France) under the conditions recommended by the supplier. A volume of $2 \mu \mathrm{l}$ of the reaction was submitted to quantitative PCR, using specific primers and the SYBR-Green PCR kit (Qiagen). Reactions were performed several times in duplicate on an Opticon apparatus (VWR, Illkirch, France). Most results were also confirmed on a Light Gycler apparatus (Roche).

The PGR cycle used was as follows: enzyme activation $-95{ }^{\circ} \mathrm{C}, 15 \mathrm{~min}$; cycles $-95^{\circ} \mathrm{C}, 15 \mathrm{~s}$; $50{ }^{\circ} \mathrm{C}, 25 \mathrm{~s} ; 72{ }^{\circ} \mathrm{C}, 18 \mathrm{~s}$ (45 times).

The specificity of the amplification was controlled by the fusion temperature of the amplicons. The size of the products was checked on agarose gels.
Oligonucleotides were designed with the Primer3 program available at the Whitehead Institute web site (www-genome.wi.mit.edu). Each oligonucleotide within a pair hybridizes on a different exon. The sequences of the oligonucleotides were as follows:

ERRa: CAAAGGCGTCTGGCTGGTCT and ACTGGATGCTCGCGTGGATG

36B4: ACGTGCTTCTTGGAGGGTTT and CGGACGTTGTGTCGAGTCTTT

Rev-erba: TGGAAGACAGGAGGGGAGTGT and CATAGTGGAAGCGTGAGGCGA

Bmall: CAGAGCGGGAGCAGGAAAAA and ACAGGTGGAAGGGGATGACG

Per2: ATGAACGGGTGGAGGAGGAA and GGGAGCTGCGAACACATCGT

Opn: TGTGCTTGGGGGAGAGAATG and TGGTCGATGTGGTCATGGCT

\section{Statistical analysis}

Relative cDNA amounts in each sample were determined by the $\Delta \Delta \mathrm{CT}$ method (using the constant 36B4 gene as an internal reference). Average values within a time group were plotted, and S.E.M. values were calculated. ANOVA analyses were used to compare each set of data. Variations were significant with at least $P<0 \cdot 05$.

\section{Results}

Genome-wide analysis of rhythmic gene expression in male mouse liver using high-density oligonucleotide DNA microarrays identified the orphan nuclear receptor $E R R a$ as a putative target of the circadian clock. ERRa showed a rhythmic expression pattern with trough and peak levels at ZT4 and ZT12-16 respectively (Fig. 1A). This cyclic expression was confirmed by quantitative PCR (QPGR) experiments performed on RNA extracted from an independent set of female animals bred in a 13h light:11h dark cycle (LD13:11; Fig. 1B left panels). As a marker of circadian clock activity, we used the Rev-erba gene that displays a robust oscillation in liver (Pineda-Torra et al. 2000, Preitner et al. 2002), and for which an expression peak was observed at the expected ZT8. To determine whether the cyclic expression of ERRa was dependent on an endogenous clock, animals kept in DD conditions (Fig 1B, right panel) were 
A)

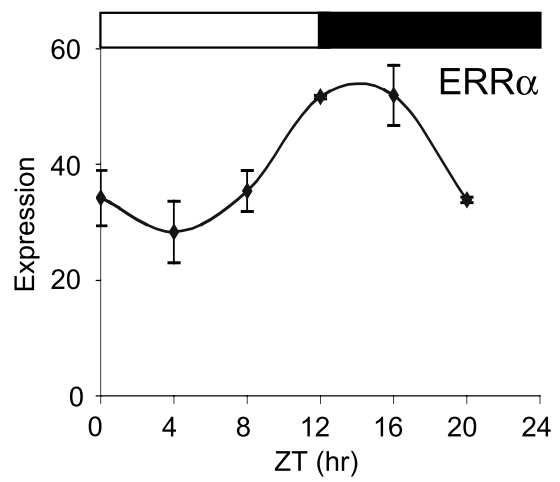

B)

Liver; L/D
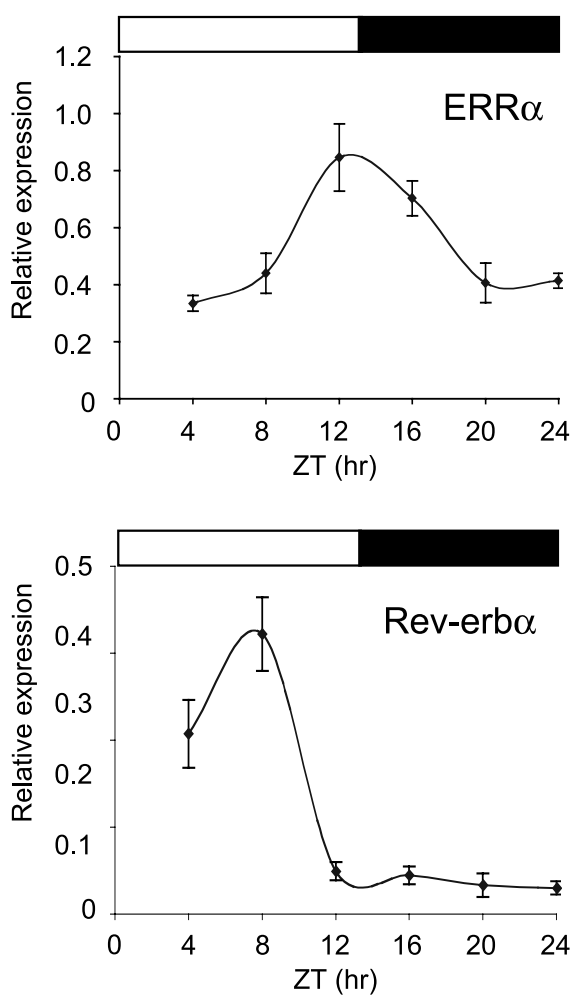

Liver; D/D
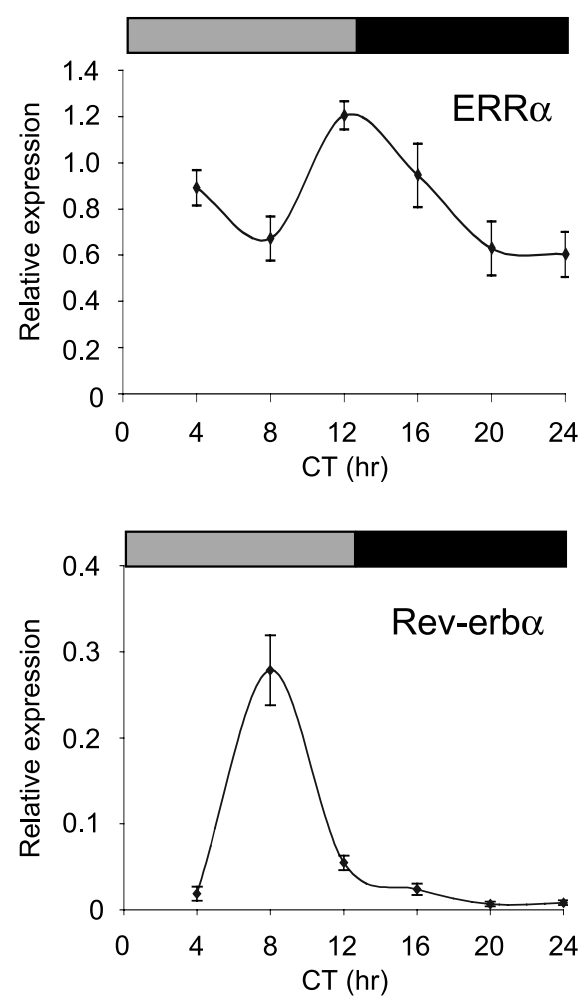

Figure 1 Rhythmic expression of ERR $\alpha$ in mouse liver. (A) cDNA array experiment. Male animals $(n=10)$ set in light/dark (LD) conditions were killed every $4 \mathrm{~h}$. RNA extracted from livers was pooled and submitted to microarray experiments. Shown is the expression of ERR $\alpha$ as a function of zeitgeber time (ZT). Error bars indicate the variations between duplicate experiments. (B) QPCR experiments. Female animals $(n=3-4)$ set in LD (left panels) or DD, (right panels) conditions were killed every $4 \mathrm{~h}$. Q PCR was performed on individually retrotranscribed liver RNA to amplify the indicated genes. Expression levels, relative to the expression of the 36B4 gene, are plotted as a function of ZT or circadian time (CT), and expressed \pm S.E.M. White, shaded and black bars at the top of the graphs indicate objective day, subjective day and night respectively. 


\section{Liver; D/D}
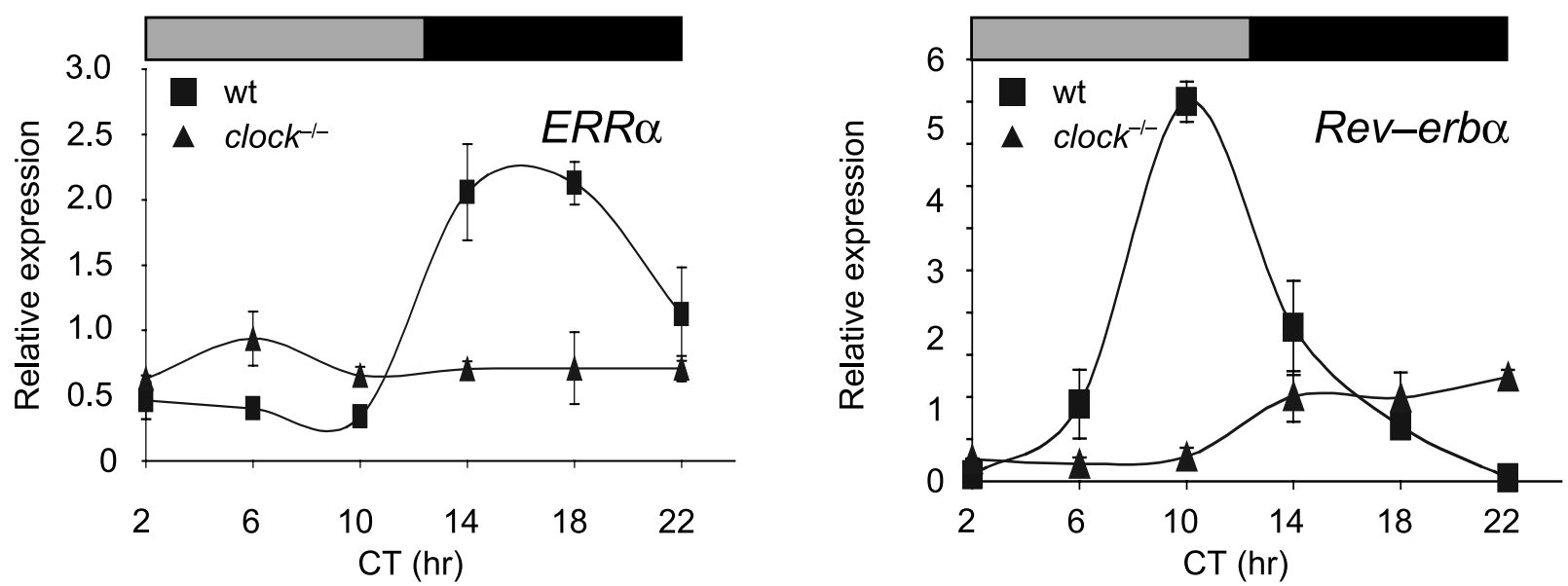

Figure 2 Circadian expression of $E R R a$ in the liver is clock-dependent. Details same as for Fig. 1B, using livers from male wild-type (squares) or clock $^{-1-}$ animals (triangles) set in DD conditions.

analyzed. For both ERRa and Rev-erba, we observed the same temporal expression pattern as in $\mathrm{LD}$ animals, indicating that ERRa is a likely target of the circadian clock in liver.

The mutation of the Clock gene in mice results in an arhythmic molecular and behavioral phenotype (King et al. 1997). To determine genetically whether ERRa is a clock-controlled gene, we analyzed its expression in livers of Clock-deficient mice set in DD conditions (Fig. 2). In these animals, ERRa expression did not vary as a function of time, whereas wild-type littermates displayed the expected rhythmicity. As a positive control, the circadian expression of Rev-erba observed in wild-type animals was abolished in Clock-deficient mice. These data indicate that ERRa is downstream of CLOCK. However, the CLOCK-BMAL heterodimer did not exert any regulatory activity on mouse ERR $\alpha$ promoter when assayed in transient transfections (data not shown), suggesting an indirect control.

The complex pattern of expression displayed by mouse ERRa includes the uterus (Bonnelye et al. 1997a), an organ that is highly sensitive to the cyclic hormonal status. The circadian expression of $E R R a$ in male and female liver therefore offers a means to study the rhythmicity of gene expression in the uterus. We analyzed the expression of $E R R a$, using RNAs extracted from mice set in LD or DD conditions (Fig. 3). In both cases, ERRa expression was found to vary over time. Expression in DD uterus reaches its maximum at ZT12 (identical to the one observed in the liver), whereas LD animals surprisingly displayed an expression peak at ZT16 (that is, $4 \mathrm{~h}$ later than in the liver). In contrast, expressions of both Rev-erba and Bmall were found to peak at identical ZT (8 and 4 respectively), independently of light conditions.

ERR $\alpha$ has been shown to be expressed in both embryonic and adult bones, and hypothesized to play an important role in the development and/or homeostasis of this tissue (Bonnelye et al. 1997b, 2001). Bone is also a hormone-responsive tissue that excretes degradation products in a circadian manner (Srivastava et al. 2001). However, circadian regulation of gene expression in bone remains to be demonstrated. We observed that Rev-erba or Bmall, two robust markers of circadian clock activity, did not display any cyclic expression in this tissue (data not shown). In contrast, ERRa exhibited a circadian expression pattern in bone with a peak at ZT12 in mice kept under LD or DD conditions (Fig. 4). Osteopontin (opn, encoding an extracellular matrix protein involved in bone remodeling) has been proposed as an ERR $\alpha$-target gene in bone (Vanacker et al. 1998). We therefore hypothesized that opn expression should follow that of ERRa. Analysis of opn expression indeed revealed a 


\section{Uterus; L/D}
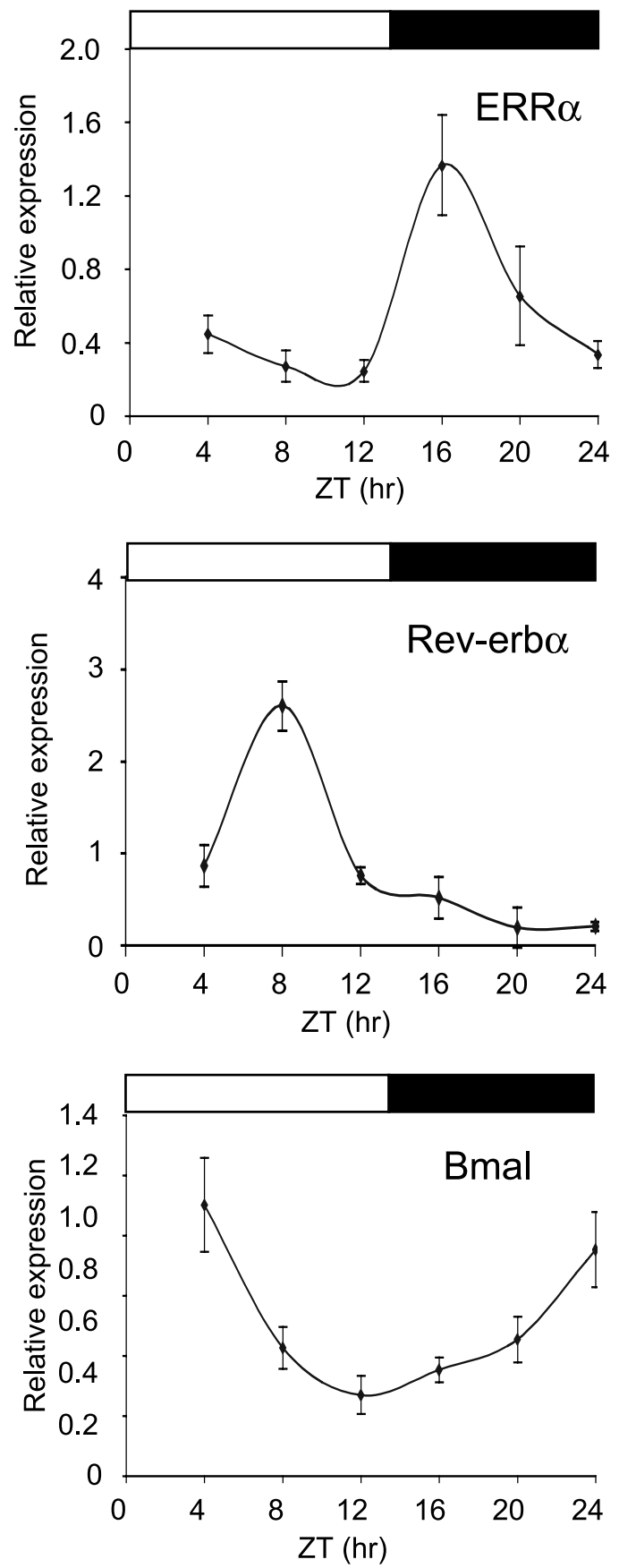

\section{Uterus; D/D}
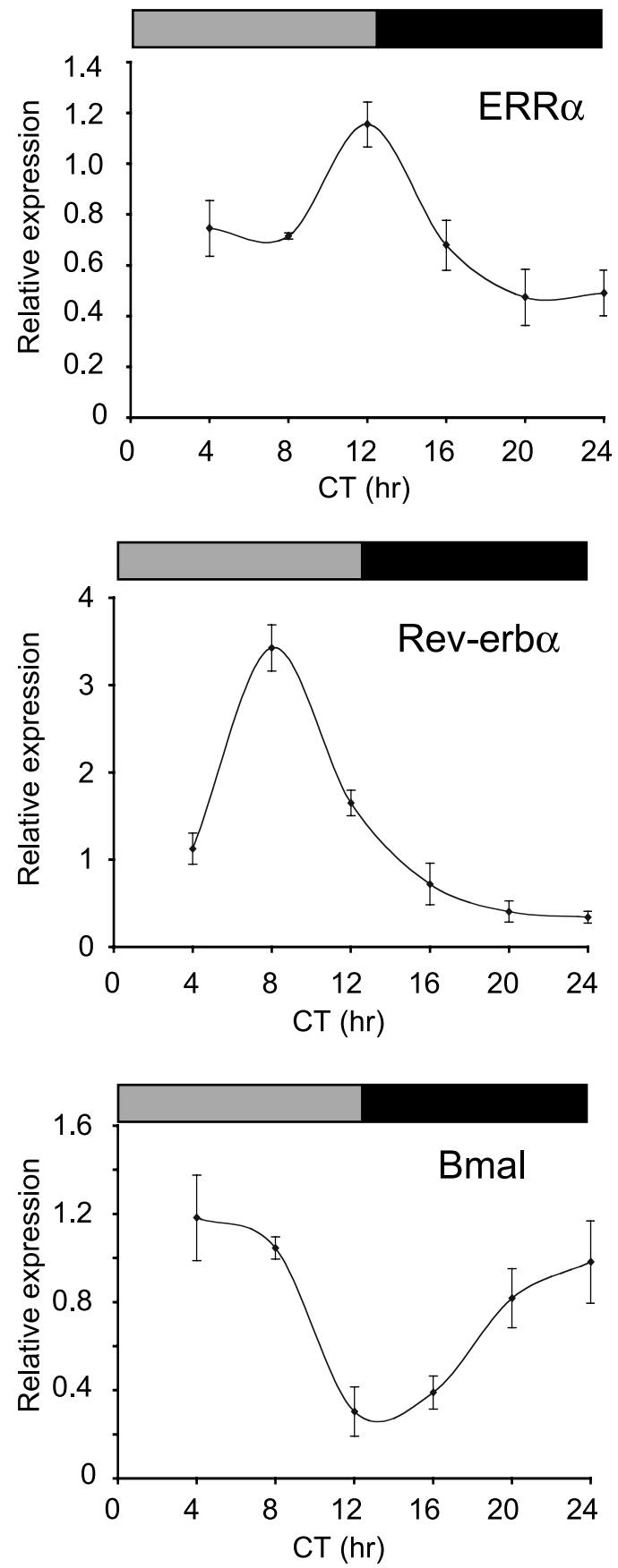

Figure 3 Circadian gene expression in mouse uterus. Details same as for Fig. 1B, using RNA extracted from uterus.

rhythmic pattern, with a maximum at ZT16. This finding suggests that ERRa is a mediator of opn circadian expression in bone. The rhythmicity of ERRa expression in bone also suggests the existence of a molecular clock in this tissue. Per2 was indeed found to be expressed in a circadian manner, peaking at ZT12, and thus revealing the existence of a peripheral clock in bone. 
Bone; L/D
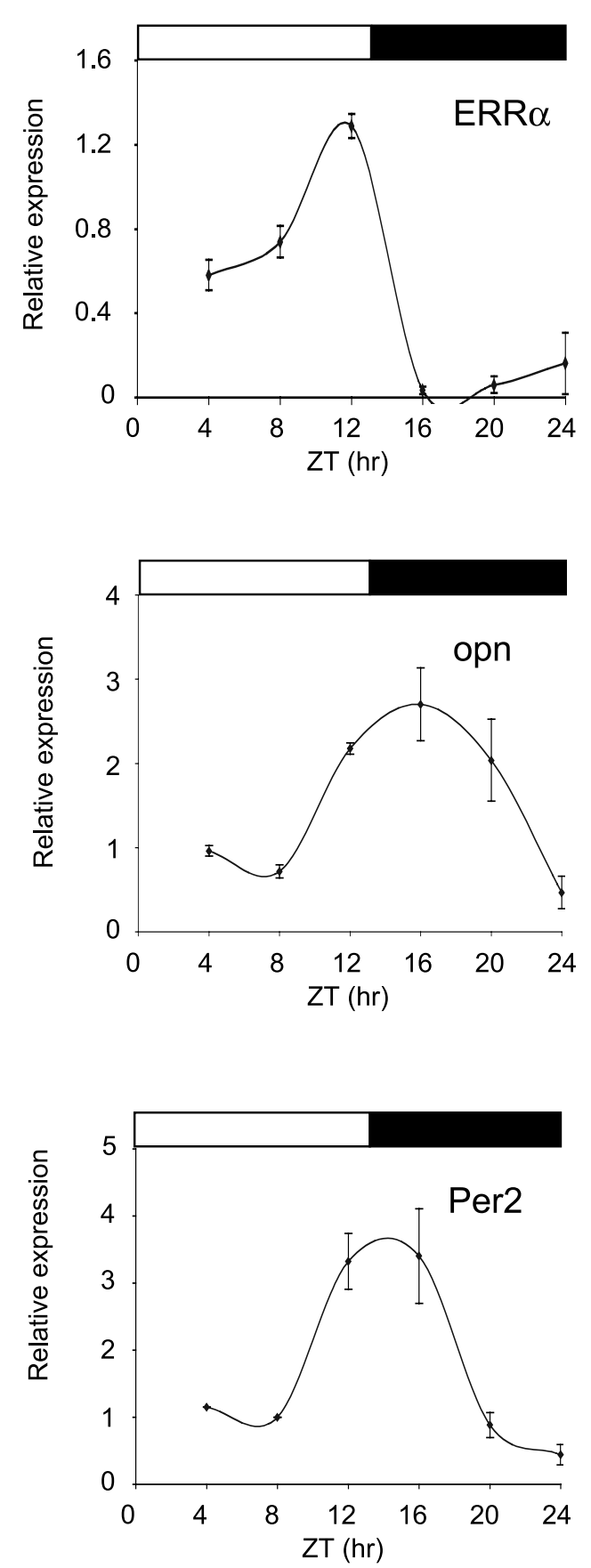

Bone; D/D
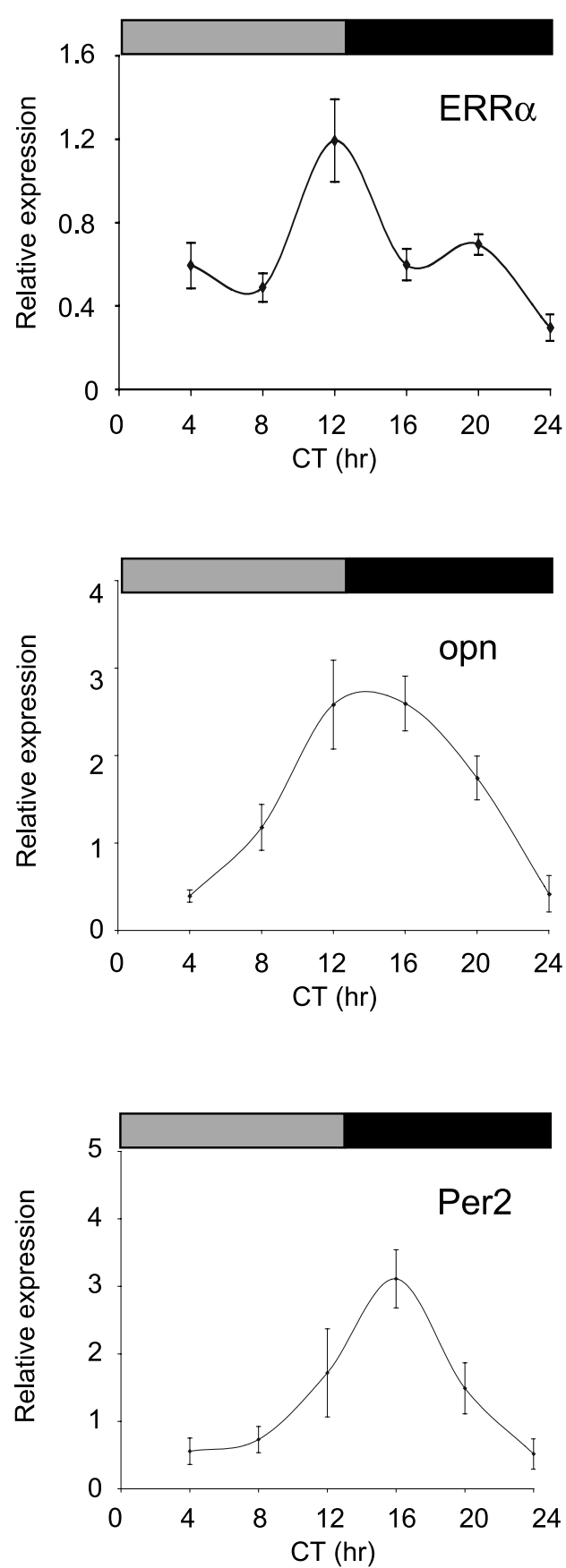

Figure 4 Circadian expression of ERRa in mouse bones. Details same as for Fig. 1B, using RNA extracted from bone-marrow-free long bones. 


\section{Discussion}

\section{Circadian regulation of ERR $a$ expression}

Circadian regulation of ERRa was observed by two different methods, namely, cDNA arrays and QPCR. Moreover, independent sets of animals, bred in different laboratories, displayed the same temporal expression, at least in liver. No sexual dimorphism was observed in the ERRa liver expression pattern. Further evidence in favor of $E R R a$ as a clock-controlled gene is adduced (i) by the study of animals kept under DD in which ERRa oscillations persist (therefore demonstrating that ERRa does not respond to light per se) and (ii) by the use of Clock mutant mice, in which expression of this gene is constant through time (demonstrating that $E R R a$ oscillations are molecular-clock-dependent). Our data are consistent with the results published by Ueda et al. (2002), in which ERRa expression was also found to peak in both LD and DD livers at ZT and circadian time (CT) 13 respectively. Gyclic expression is not a general property of ERR subfamily members, since, for instance, $E R R \gamma$ expression in liver does not vary with time (data not shown). ERRa expression also cycles in the uterus and in long bones. cDNA arrays studies on SCN, liver and heart have shown that, although about $10 \%$ of genes were found to oscillate in a given organ, only a subset of them are cyclically regulated in different tissues (Albrecht \& Eichele 2003 and references therein). Cyclicity of ERRa uterine expression can be observed in mice kept under both LD and DD conditions. However, the time of maximal expression of this gene shows a $4 \mathrm{~h}$ delay in the LD uterus compared with liver and bone, a difference abolished in DD animals. Despite this unexplained difference between LD and DD mice, ERRa clearly displays a circadian regulation of expression.

Ratl fibroblasts have been proposed as a cellculture model for the study of circadian rhythm, since these cells exhibit oscillations of clock-control gene expression upon high-serum shock (Balsalobre et al. 1998, Rosbach 1998, Yagita et al. 2001). Under these conditions, we could detect such a pattern for Rev-erba, but not for ERRa (data not shown). However, only $2 \%$ of total genes are estimated to oscillate in Ratl cells, whereas this number reaches about $10 \%$ in vivo (Panda et al. 2002, Albrecht \& Eichele 2003).

Transient cotransfection experiments in COS cells did not reveal any regulation of a $1.3 \mathrm{~kb}$ mouse ERRa promoter fragment by PER2, REV-ERB $\alpha$ or GLOCK-BMAL heterodimer, used either alone or in combination (data not shown). In contrast, the mouse Rev-erb $\alpha$ promoter was regulated by CLOCK-BMAL (positively), REVERB $\alpha$ itself and PER2 (negatively), as expected (Preitner et al. 2002, Triqueneaux \& Laudet, unpublished). Although an output gene of the molecular clock, ERRa is therefore not directly controlled by circadian proteins (in contrast to Rev-erba). The existence of a yet unknown intermediate or intermediates between the molecular clock and ERRa expression must be hypothesized.

\section{Circadian rhythm and hormone-responsive tissues}

Circadian oscillations of hormone levels in mammalian blood have long been recognized and have been linked to behavioral processes. For instance, the concentrations of various steroid hormones, such as testosterone, estrogens and glucocorticoids, peak in human blood during the later part of the night (Ankarberg \& Norjavaara 1999, Gudmundsson et al. 1999, Mitamura et al. 2000). These elevations facilitate the renewal of physical activity during the early wake phase. Another example is the peak FSH/LH expression that occurs every afternoon in female mice, independently of the phase of the ovarian cycle (Krajnak et al. 1998). FSH/LH excretion is also upregulated during proestrus. Thus, on the afternoon of this particular day, maximum concentrations of gonadotropins are achieved that allow synchronization of ovulation (that is, the efficiency of the egg release from the ovary that occurs a few hours after the FSH/LH surge) with behavior (that is, mating in the middle of the night). The converse phenomenon, that is, hormones influencing circadian rhythm, has also been documented. For instance, in rodents, inappropriate treatment with estrogens or testosterone can perturbate the circadian rhythm of physical activity (Morin et al. 1977, Jechura et al. 2000). However, no explanation of this phenomenon has been proposed in terms of gene-expression regulation, although steroid hormones act as transcription modulators through their cognate receptor.

Circadian rhythm is mostly studied in male animals for fear of interference with the sexual 
rhythm, which is much more influential in females. In particular, the uterus, a paradigm of hormonesensitive organs, undergoes profound remodeling, implicating cellular proliferation and differential gene expression according to the levels of circulating sex hormones which reflect the phase of the ovarian cycle. On the other hand, most clock genes are expressed in the uterus (Johnson et al. 2002), but their rhythmicity has not been demonstrated. Our data show that the mRNA of two of these genes, Bmal1 and Rev-erba, oscillate in a manner comparable to what can be observed in the liver, demonstrating the existence of an autonomously functioning clock in the uterus.

It is unlikely that the expression peaks of these genes reflect the sex hormone status rather than autonomous circadian control. Indeed, QPCR experiments demonstrated that the expression of various genes regulated according to the stage of estrous cycle, such as Wnt7a (Miller et al. 1998) and PR (progesterone receptor) (Punyadeera et al. 2003 and references therein), does not significantly vary between the mice groups that we studied (data not shown). This is also the case for ERa (estrogen receptor alpha), in both uterus and bone. This suggests that no time group is a particular phase of the ovarian cycle. Bone expression of ERa is also not regulated in a circadian way (data not shown). $E R R a$ has been suggested to be an estrogen-target gene (Liu et al. 2003). However, our unpublished experiments with immature or mature mice failed to detect any effect of estrogen treatment on ERRa expression in uterus and bone (data not shown). Furthermore, the timing of the estrogen peak (ZT 20-24; Mitamura et al. 2000), as opposed to that of ERRa expression (ZT12-16), renders it unlikely that ERRa oscillations are mostly controlled by estrogens. It could still be that circadian- and sex hormone-induced gene regulation of ERRa overlap. This has, for instance, been shown for FSH/LH expression, which is regulated both by the sex hormone status (maximum in proestrus) and by circadian rhythm through vasoactive intestinal polypeptide produced in the SCN (Krajnak et al. 1998).

\section{Circadian rhythm in bone}

Most tissues and organs contain an endogenous, autonomously functioning clock that is synchro- nized by signals emanating from the SCN. To date, only the testis has been shown not to support any circadian clock, although contradictory results have been published (Zylka et al. 1998, Morse et al. 2003). In this respect, bone has never been studied, although indications exist in this direction. Indeed, the rates of bone formation and resorption are enhanced during the night (Seibel et al. 2002 and references therein). Moreover, the blood concentration of markers of bone formation and resorption, such as osteocalcin and alkaline phosphatase, varies according to the nycthemeral cycle. However, it is not known whether expression or excretion of these products is involved in this regulation. Again, no molecular study has been performed to demonstrate the existence of rhythmic gene expression. We found comparable profiles of temporal ERRa expression in both bone and liver, in which clock dependence clearly proves the circadian nature of ERRa gene expression. Moreover, the opn gene that has been suggested as an ERR $\alpha$-target gene in bone (Vanacker et al. 1998) is also expressed in a circadian manner, and its expression peak immediately follows that of ERRa.

We also examined the temporal expression profiles of various clock components in bone. Our analysis revealed an absence of rhythmicity for Bmall (which was barely detectable) and Rev-erba (although present in amounts comparable to those of the liver) (data not shown). Paralogs of these two genes, Mop9/Bmal2 (Hogenesch et al. 2000, Okano et al. 2001) and Rev-erb $\beta$ respectively, were undetectable in our QPCR experiments (data not shown). This renders unlikely a functional compensation between paralogs, as has been found for NPAS2, which, in the forebrain, substitutes for its homolog CLOCK (active, for example, in the SCN) in dimerizing with the BMAL product, and fulfills equivalent functions (Rieck et al. 2001, Dudley et al. 2003). Essential components of the molecular clock are thus either not expressed or evenly expressed in bone. Yet an autonomous although unconventional clock oscillates in bone, as demonstrated by the oscillations of Per2 (as a clock-controlling gene), ERRa (as an indirect output gene) and opn (as a possible consequence of ERRa rhythmic expression) mRNA levels. The study of the regulation of ERRa expression in bone might help to uncover the components of the circadian clock in this atypical tissue. 


\section{Acknowledgements}

We thank the Centre National de la Recherche Scientifique (CNRS), Ligue contre le Cancer, comités Ardèche, Drôme and Loire, and Ecole Normale Supérieure de Lyon for financial support. $\mathrm{BH}$ is supported by Proskelia Pharmaceuticals (Romainville, France). RNA from clock mutant animals was a generous gift from Joseph S. Takahashi (Northwestern University, Evanston, IL, USA). We thank Frédéric Flamant for critical reading of the manuscript.

\section{References}

Albrecht U \& Eichele G 2003 The mammalian circadian clock. Current Opinion in Genetics and Development 13 271-277.

Ankarberg C \& Norjavaara E 1999 Diurnal rhythm of testosterone secretion before and throughout puberty in healthy girls: correlation with $17 \beta$-estradiol and dehydroepiandrosterone sulfate. Fournal of Clinical Endocrinology and Metabolism 84 975-984.

Balsalobre A, Damiola F \& Schibler U 1998 A serum shock induces circadian gene expression in mammalian tissue culture cells. Cell 93 929-937.

Bonnelye E, Vanacker JM, Spruyt N, Alric S, Fournier B, Desbiens $\mathrm{X} \&$ Laudet V 1997 a Expression of the estrogen-related receptor 1 (ERR-1) orphan receptor during mouse development. Mechanisms of Development 65 71-85.

Bonnelye E, Vanacker JM, Dittmar T, Begue A, Desbiens X, Denhardt DT, Aubin JE, Laudet V \& Fournier B $1997 b$ The ERR-1 orphan receptor is a transcriptional activator expressed during bone development. Molecular Endocrinology 11 905-916.

Bonnelye E, Merdad L, Kung V \& Aubin JE 2001 The orphan nuclear estrogen receptor-related receptor alpha (ERR alpha) is expressed throughout osteoblast differentiation and regulates bone formation in vitro. Fournal of Cell Biology 153 971-984.

Bunger MK, Wilsbacher LD, Moran SM, Clendenin C, Radcliffe LA, Hogenesch JB, Simon MC, Takahashi JS \& Bradfield CA 2000 Mop3 is an essential component of the master circadian pacemaker in mammals. Cell $\mathbf{1 0 3}$ 1009-1017.

Damiola F, Le Minh N, Preitner N, Kornmann B, Fleury-Olela F \& Schibler U 2000 Restricted feeding uncouples circadian oscillators in peripheral tissues from the central pacemaker in the suprachiasmatic nucleus. Genes and Development 14 2950-2961.

Delaunay F \& Laudet V 2002 Circadian clock and microarrays: mammalian genome gets rhythm. Trends in Genetics 18 595-597.

Dudley CA, Erbel-Sieler C, Estill SJ, Reick M, Franken P, Pitts SN \& McKnight SL 2003 Altered patterns of sleep and behavioral adaptability in NPAS2-deficient mice. Science 301 379-383.

Fu L \& Lee CC 2003 The circadian clock: pacemaker and tumor suppressor. Nature Reviewes Cancer 3 350-361.

Giguère V 2002 To ERR in the estrogen pathway. Trends in Endocrinology and Metabolism 13 220-225.

Giguère V, Yang N, Segui P \& Evans RM 1988 Identification of a new class of steroid hormone receptors. Nature 331 91-94.

Grundschober C, Delaunay F, Pühlhofer A, Triqueneaux G, Laudet V, Bartfai T \& Nef P 2001 Circadian regulation of diverse gene products revealed by mRNA expression profiling of synchronized fibroblasts. Fournal of Biological Chemistry 276 46751-46758.

Gudmundsson A, Goodman B, Lent S, Barczi S, Grace A, Boyle L, Ershler WB \& Carnes M 1999 Effects of estrogen replacement therapy on the circadian rhythms of serum cortisol and body temperature in postmenopausal women. Experimental Gerontology 34 809-818.

Hogenesch JB, Gu Y-Z, Moran SM, Shinomura K, Radcliff LA, Takahashi JS \& Bradfield CA 2000 The basic helix-loop-helixPAS protein MOP9 is a brain-specific heterodimeric partner of circadian and hypoxia factors. Fournal of Neuroscience 83 1-5.

Hong H, Yang L \& Stallcup MR 1999 Hormone-independent transcriptional activation and coactivator binding by novel orphan nuclear receptor ERR3. Journal of Biological Chemistry 274 22618-22626.

Horard B \& Vanacker JM 2003 Estrogen receptor-related receptors: orphan receptors desperately seeking a ligand. Fournal of Molecular Endocrinology 31 349-357.

Jechura TJ, Walsh JM \& Lee TM 2000 Testicular hormones modulate circadian rhythms of the diurnal rodent. Hormones and Behaviour 38 243-249.

Johnson MH, Lim A, Fernando D \& Day ML 2002 Circadian clockwork genes are expressed in the reproductive tract and conceptus of the early pregnant mouse. Reproductive BioMedicine Online 4 140-145.

King DP, Zhao Y, Sangoram AM, Wilsbacher LS, Tanaka M, Antoch MP, Steeves TDL, Hotz Vitaterna M, Kornhauser JM, Lowrey PL et al. 1997 Positional cloning of the mouse circadian gene. Cell $\mathbf{8 9} 641-653$.

Krajnak K, Kashon ML, Rosewell KL \& Wise PM 1998 Sex differences in the daily rhythm of vasoactive intestinal polypeptide but not arginine vasopressin messenger ribonucleic acid in the suprachiasmatic nuclei. Endocrinology 139 4189-4196.

Laudet V \& Gronemeyer H 2002 The Nuclear Receptor Factbooks. San Diego, CA: Academic Press.

Liu D, Zhang Z, Gladwell W \& Teng CT 2003 Estrogen stimulates estrogen-related receptor $\alpha$ gene expression through conserved hormone response elements. Endocrinology $1444894-4904$.

Miller C, Pavlova A \& Sassoon DA 1998 Differential expression patterns of Wnt genes in the murine female reproductive tract during development and the estrous cycle. Mechanisms of Development 76 91-99.

Mitamura R, Yano K, Suzuki N, Ito Y, Makita Y \& Okuno A 2000 Diurnal rhythms of luteinizing hormone, follicle-stimulating hormone, testosterone, and estradiol secretion before the onset of female puberty in short children. Fournal of Clinical Endocrinology and Metabolism 85 1074-1080.

Morin LP, Fitzgerald KM \& Zucker I 1977 Estradiol shortens the period of hamster circadian rhythms. Science 196 305-307.

Morse D, Germakian N, Brancorsini S, Parvinen M \& Sassone-Corsi P 2003 No circadian rhythms in testis: expression is independent and developmentally regulated in the mouse. Molecular Endocrinology 17 141-151.

Oishi K, Fukui H \& Ishida N 2000 Rhythmic expression of BMAL1 mRNA is altered in mutant mice: differential regulation in the suprachiasmatic nucleus and peripheral tissues. Biochemical and Biophysical Research Communications 268 164-171.

Okano T, Sasaki M \& Fukada Y 2001 Cloning of mouse BMAL2 and its daily expression profile in the suprachiasmatic nucleus: a remarkable acceleration of sequence divergence after gene duplication. Neuroscience Letters 300 111-114.

Oster H, Baeriswyl S, van der Horst GTJ \& Albrecht U 2003 Loss of circadian rhythmicity in aging mutant mice. Genes and Development 17 1366-1379.

Panda S, Antoch MP, Miller BH, Su AI, Schook AB, Straume M, Schultz PG, Kay SA, Takahashi JS \& Hogenesch JB 2002 Coordinated transcription of key pathways in the mouse by the circadian clock. Cell 109 307-320.

Pineda-Torra I, Tsibulsky V, Delaunay F, Sladin R, Laudet V, Fruchart J-C, Kosykh V \& Staels B 2000 Circadian and 
glucocorticoid regulation of Rev-erb $\alpha$ expression in liver. Endocrinology 141 3799-3806.

Preitner N, Damiola F, Lopez-Molina L, Zakany J, Duboule D, Albrecht U \& Schibler U 2002 The orphan nuclear receptor REV-ERB $\alpha$ controls circadian transcription within the positive limb of the mammalian circadian oscillator. Cell 110 251-260.

Punyadeera C, Verbost P \& Groothuis P 2003 Oestrogen and progestin responses in human endometrium. Fournal of Steroid Biochemistry and Molecular Biology 84 393-410.

Rieck M, Garcia JA, Dudley C \& McKnight SL 2001 NPAS2: an analog of clock operative in the mammalian forebrain. Science $\mathbf{2 9 3}$ 506-509.

Rosbach M 1998 Why the Rat-1 fibroblast should replace the SCN as the in vitro model of choice. Cell 93 917-919.

Schibler U \& Sassone-Corsi P 2002 A web of circadian pacemakers. Cell 111 919-922.

Schultz TF \& Kay SA 2003 Circadian clocks in daily and seasonal control of development. Science 301 326-328.

Seibel MJ, Eastell R, Gundberg CM, Hannon R \& Pols HAP 2002 Biochemical markers of bone metabolism. In Principles of Bone Biology, eds JP Bilezikian, LG Raisz and GA Rodan, pp 1543-1571. San Diego, CA: Academic Press.

Srivastava AK, Bhattacharyya S, Li X, Mohan S \& Baylink DJ 2001 Circadian and longitudinal variation of serum C-telopeptide, osteoclacin, and skeletal alkaline phosphatase in $\mathrm{C} 3 \mathrm{H} / \mathrm{HeJ}$ mice. Bone 29 361-367.
Stokkan K-A, Yamazaki S, Tei H, Sakaki Y \& Menaker M 2001 Entrainment of the circadian clock in the liver by feeding. Science $291490-493$.

Ueda HR, Chen W, Adachi A, Wakamatsu H, Hayashi S, Takasugi T, Nagano M, Nakahama K, Suzuki Y, Sugano S et al. 2002 A transcription factor response element for gene expression during circadian night. Nature 418 534-539.

Vanacker JM, Delmarre C, Guo X \& Laudet V 1998 Activation of osteopontin promoter by the orphan nuclear receptor estrogen receptor related alpha. Cell Growth and Differentiation 9 1007-1014.

Van der Horst GTJ, Muijtjens M, Kobayashi K, Takano R, Kanno S, Takao M, de Wit J, Verkerk A, Eker APM, van Leenen D et al. 1999 Mammalian Cryl and Cry2 are essential for maintenance of circadian rhythms. Nature 398 627-630.

Van Gelder RN, Herzog ED, Schawartz WJ \& Taghert PH 2003 Circadian rhythms: in the loop at last. Science $\mathbf{3 0 0} 1534-1535$.

Yagita K, Tamanini F, van der Horst GTJ \& Okamura H 2001 Molecular mechanisms of the biological clock in cultured fibroblasts. Science 292 278-281.

Zylka MJ, Shearman LP, Weaver DR \& Reppert SM 1998 Three homologs in mammals: differential light responses in the suprachiasmatic circadian clock and oscillating transcripts outside of brain. Neuron 20 1103-1110.

Received in final form 26 March 2004 Accepted 13 April 2004 